1988;11:226-243

15. Larson EL, Eke PI, Laughon BE. Efficacy of alcohol-based hand rinses under frequent-use conditions. Antimicrob Agents Chemother 1986;30:542-544

16. Ojajarvi J. Effectiveness of hand washing and disinfection methods in removing transient bacteria after patient nursing. J Hyg (Camb) 1980;85:193-203.

17. Rotter ML. Hand washing and hand disinfection. In: Mayhall CG, ed. Hospital Epidemiology and Infection Control. Baltimore, MD: Williams \& Wilkins; 1996:1052-1068.

18. Dineen P, Hildick-Smith G. Antiseptic care of the hands. In: Maibach HI, Hildick-Smith G, eds. Skin Bacteria and Their Role in Infection. New York, NY: McGraw-Hill; 1965:291-309.

19. Steere AC, Mallison GF. Handwashing practices for the prevention of nosocomial infections. Ann Intern Med 1975;83:683-690.

20. Ollmar S, Nyren M, Nicander I, Lemtestam L. Electrical impedance compared with other non-invasive bioengineering techniques and visual scoring for detection in irritation in human skin. Br J Dermatol $1994 ; 130: 29-36$.
21. Klein G, Grubauer G, Fritsch P. The influence of daily dish-washing with synthetic detergent on human skin. J Dermatol 1992;127:131-137.

22. Rotter ML, Koller W, Neumann R. The influence of cosmetic additives on the acceptability of alcohol-based hand disinfectants. J Hosp Infect 1991;18(suppl B):57-63.

23. Doebbeling BN, Stanley GL, Sheetz CT, Pfaller MA, Houston AK, Annis $\mathrm{L}$, et al. Comparative efficacy of alternative hand-washing agents in reducing nosocomial infections in intensive care units. $N$ Engl $J$ Med 1992;327:88-93.

24. Kaplan LM, McGuckin M. Increasing handwashing compliance with more accessible sinks. Infect Control 1986;7:408-410.

25. Voss A, Widmer AF. No time for handwashing!? Handwashing versus alcoholic rub: can we afford 100\% compliance? Infect Control Hosp Epidemiol 1997;18:205-208.

26. Larson EL, Eke PI, Wilder MP, Laughon BE. Quantity of soap as a variable in handwashing. Infect Control 1987;8:371-375.

27. Larson EL. APIC guideline for handwashing and hand antisepsis in health care settings. Am J Infect Control 1995;23:251-269.

\title{
Reducing IV Device-Associated Infections
}

\section{Gina Pugliese, RN, MS \\ Martin S. Favero, PhD}

Intravenous devices are a leading cause of nosocomial infections (NIs) that can be reduced by specific prevention strategies and improved guidelines for their use. However, the impact of a combination of these strategies on vascular access infection (VAI) rates in ICUs remains to be determined. Investigators from the medical ICU and the infection control program at the University of Geneva Hospitals, Switzerland, implemented a multipleapproach prevention program to decrease VAI. Between October 1995 and November 1997 , a total of 3,154 critically ill patients admitted to the medical ICU was included in a cohort study with longitudinal evaluation of an overall catheter-care policy and based on an educational campaign for VAI and device utilization and care.

The intervention strategy was implemented in March 1997, and its impact was measured during an 8-month intervention period. An educational campaign consisting of 30-minute slide shows was initiated and included detailed information on clinical pathways for VAI, and device maintenance and utilization, based on previously identified risk factors. The guidelines cov- ered the following: preparation of the material to avoid any interruption during insertion; skin preparation and antisepsis; maximal barrier precautions; and subclavian or wrist vein as standard insertion sites. Hand hygiene was strongly emphasized before and after insertion, replacement, or the manipulation of any vascular device. Central lines were not routinely replaced, but were changed over a guidewire in case of clinical sepsis without a documented source of infection. Prompt removal of any device not intended for use was strongly recommended.

A total of 613 infections occurred in 353 patients (19.4 infections $/ 100$ admis sions). Following the intervention, the incidence-density of exit-site catheter infection decreased from 9.2 to 3.3 episodes per 1,000 patient-days, and bloodstream infections (BSIs) decreased from 11.3 to 3.8 per 1,000 patient-days due to reduced rates of both microbiologically documented infections and clinical sepsis. Overall, the incidence of all ICU-acquired NIs was reduced by $35 \%$, from 52.4 to 34.0 episodes per 1,000 patient-days.

The results demonstrate the impact of a multiple-approach intervention strategy on bloodstream and catheter-related infection rates, as well as on the overall incidence of ICU-acquired NI. Although infection rates before the intervention (ie, 6.6 episodes of microbiologically documented BSIs $/ 1,000$ central venous catheter-days) were within the accepted limits, the study confirmed that a large proportion of NI related to extrinsic factors is still preventable and that intervention strategy targeted at vascular access can have a significant impact on the overall incidence of NIs.

The investigators believe that the multidimensional intervention was successful in decreasing infection rates because it targeted multiple behavioral and catheter-care related factors. They note that the strategy was just as successful in reducing VAI rates as the use of newly introduced antibiotic-/antisepticcoated catheters, which have the poten tial of being associated with acquisition of antibiotic resistance and allergic or toxic reaction. They estimated that this program and infections prevented, at a minimum, equal the annual salary of three full-time infection control practitioners.

FROM: Eggimann P, Harbarth S, Constantin M-N, Touveneau S, Chevrolet J-C, Pittet D. Impact of a prevention strategy targeted at vascular-access care on incidence of infections acquired in intensive care. Lancet 2000;355:1864-1868. 